\title{
Renewable Energy Investment in Malaysia: An Integrated Model in Evaluating Public Decision Making Process
}

\author{
N. Mat Husin and B. Alrazi
}

\begin{abstract}
Rapid depletion of fossil fuel reserves as well as climate change has driven the world including Malaysia towards renewable energy (RE) sources which are untapped and environmentally friendly. Through a feed-in-tariff system, Malaysia has set a target of increasing its RE capacity to $11 \%$ of total capacity mix of electricity generation by year 2020 . The system is supported with five strategic thrusts (ST) of National RE policy which include providing a conducive business environment for RE (ST2). Despite the existence of ST2, to the knowledge of this research, there has been no effort being made to better understand the variety of decisions taken by Malaysian $R E$ investors to invest in $R E$. Through a review of $R E$ literature, this study develops an integrated decision making model, to be tested on Malaysian RE investors, by using Theory of Planned Behavior as the underlying framework. The theory is then modified to incorporate previous drivers introduced in previous RE literature that largely based on behavioral finance and institutional theory. Given that RE in Malaysia is currently reported at only at $1 \%$ of total capacity mix as compared to the $11 \%$ target, the model will help Malaysian regulators to better leverage all drivers that stimulate $\mathrm{RE}$ investment and design a more conducive business environment for RE.
\end{abstract}

Index Terms-Renewable energy, investment, decision making, Malaysia.

\section{INTRODUCTION}

Rising concern over climate change and pollution is promoting many policy makers to pass regulation to encourage renewable energy (RE) generation. It is expected that the RE sector will be the fastest growing component of world primary energy demand with an annual growth rate of $6.7 \%$ [1]. Malaysia, in particular, established a comprehensive National RE Policy and Action Plan in year 2009 leading to a proposal to introduce a Feed-in-Tariff (FiT) system. In June 2011, the system received the royal consent and it is currently managed by the Sustainable Energy Development Authority (SEDA). The FiT system offers RE investors in Malaysia, commonly known as the Feed-in-Approval Holders (FiAHs), a return set at a FiT rate for each unit of electricity fed into the grid, and obliges the Distribution Licensees i.e. the registered power companies to buy the electricity from FiAHs for specific duration.

It is reported that the current capacity mix of RE in Malaysia is less than $1 \%$ of total capacity mix of Malaysia electricity generation [2]. The low percentage could be

Manuscript received February 25, 2016; revised May 20, 2016. This work was supported by Malaysian Ministry of Higher Education under the Grant 20140131FRGS

The authors are with the Department of Accounting, National Energy University, Malaysia (e-mail: hayati@uniten.edu.my, bakhtiar@uniten.edu.my). contributed by the fact that Malaysia is implementing a controlled FiT system where there is a quota being set for RE investment. An ambitious plan has been drafted by Malaysia government whereby RE should account for $985 \mathrm{MW}$ or $5.5 \%$ share of the energy mix by 2015 and by 2020, the target is for $\mathrm{RE}$ to comprise $11 \%$ or $2,080 \mathrm{MW}$ of overall electricity generation in the country. With these targets, it is expected that the RE quota will keep on increase and massive private investment is expected to be made. To encourage RE investment, Malaysia has also crafted its' National RE Policy and Action Plan which is accompanied by five strategic thrusts (ST) including ST 2: Provide Conducive Business Environment for RE. Among initiatives being stipulated under ST2 is to promote RE businesses among small-medium enterprises (SMEs) and manufacturing companies, providing long term low interest financing, and developing a standard evaluation process.

Despite the long list of initiatives introduced under ST 2 as well as under the other four STs, the list represents what regulators believe as factors that can encourage investment in RE. There has been little consideration being made on what can actually drive private companies and individual to invest in RE technologies. Furthermore, against the positive response of RE investment in Malaysia, the uptake for FiT system has been dominated by solar PV [3]. The uneven RE mix can create an uneven bargaining position for potential power generators [3] as well as cause a premature extinction of technological alternatives with potentially superior performance [4]. The situation raise a concern on how well we understand Malaysian investors in their decision to allocate capital to different types of RE technologies.

Therefore, a better understanding on the variety of stances taken by potential RE investors could better leverage all drivers that stimulate RE investment. In the RE literature, there is a recurring theme of study that looks at the risk and return of RE investment across different geographical areas and types of RE technologies (see for example [1], [5], [6]). While these world of 'rationale' finance offer a quantify evidence of RE investment, not all potential investors will have all the information available to comprehensively judge the actual levels of risk and return before taking an investment decision in RE [7]. It is also important for policy makers to manage expectations that can be learned from exploring the real-world decision making processes surrounding all these potential RE investors.

Thus, taking into consideration that large RE investment is still needed before Malaysia can achieve its target, the lack of deliberation on the real drivers leading to investors decision to invest in RE, and the need to also consider less rational, broader social and psychological factors, this research aim to develop an investment decision model that explore the drivers 
for RE investment from the investors' perspective. The understanding of investors' decision making process will help regulators to design a more effective policy instruments to support the market deployment of RE technologies. To the knowledge of this research, this type of study has never been conducted within the context of RE environment in Malaysia.

\section{RE INITIATIVES IN MALAYSIA}

In year 2009, a National RE Policy and Action Plan was established with the aim to enhance the utilization of indigenous RE resources and contribute towards national electricity supply security and sustainable socio-economic development. The policy is accompanied by five STs to facilitate the growth of RE industry. Recently, the policy is further enhanced with the formulation of Economic Transformation Program (ETP), launched in September 2010.

The ETP through EPP 10 of oil, gas and energy sector was launched with an objective to harness $\mathrm{RE}$ as a viable alternative to reduce Malaysian reliance on fossil fuels, minimize carbon emissions, encourage job creation, and spur foreign direct investments [2]. To support the National RE Policy and Action Plan and EPP 10, Malaysia has opted to use the FiT system as a mechanism to attract the public as well as companies to invest in RE. Under the administration of SEDA, the system was officially launched in year 2011 and offers the investors a chance to invest in a choice of four RE technologies or resources i.e. biogas, biomass, small hydropower and solar PV. It is clear, therefore, in addition to its environmental objective, an investment in RE will also lead to socio-economic impact. [8], for example, claims that an investment in RE will lead to a minimum RM 2.1 billion savings of external cost to mitigate $\mathrm{CO} 2$ emissions; minimum RM 19 billion of loan values for RE projects, which will provide local banks with new sources of revenues (at $80 \%$ debt financing for RE projects); minimum RM 70 billion of RE business revenues generated from RE power plants operation, which can generate tax income of minimum RM 1.75 billion to Government; and 50,000 jobs created to construct, operate and maintain RE power plants (on the basis of 15-30 job per MW).

With the great potential of environmental and socio-economic impact of RE investment, Malaysia has set a target for RE to account for $5.5 \%$ share of the energy mix by 2015 and by 2020 , the target is for RE to comprise $11 \%$ or $2,080 \mathrm{MW}$ of overall electricity generation in the country. It is claimed that as compared to other countries in Southeast Asia, Malaysia has one of the most sophisticated FiT systems [9] and the total operational RE plant capacity is showing an upward trend This promising data, however, only account for $1 \%$ of Malaysia current total capacity of electricity mix.

Despite the existence of four available technologies and the increasing trend of RE investment, [9] predicts that the investment appetite is looking much brighter for solar PV taking up $30 \%$ of the total capacity by 2030 . This positive prospect, however, create a concern to SEDA leading to the announcement of several new plans to address the uneven RE mix [3]. Among the propose plans is to introduce a FiT system for new RE technologies i.e. thermal and wind energy which currently undergoing a feasibility study [3].

The potential environmental and socio-economic benefits of RE, the uneven RE mix, the prospects of adding more RE technologies, and most importantly Malaysian government commitment to meet its RE aim has made it crucial to develop an investment decision model that account for investors real-decision making process in allocating capital to different type of RE technologies.

\section{DRIVERS AFFECTING INVESTMENT DECISION IN RE}

While there have been lots of literature produced on RE, much of the focus has been on analyzing different support scheme available to support regulators' RE initiative (see for example [10]-[12]). The review shows FiT system has been among the popular choice among the scholars. [10], for example, highlight the benefits and drawbacks of uncontrollable FiT system on the PV market in Italy.

As FiT system has been chosen as the support scheme for Malaysian RE investment, the scholarly attention is moved to looking at what policy makers can do to learn from investors' decision making to design even better FiT policies. A number of RE scholars have taken the approach of applying the fundamental determinants of investment in finance theory by analyzing the risk, return, and the resulting cost of capital of RE investment. [6], for example, develop a model for investing in RE in the framework of Spanish electricity market in a way that risk is minimized and the return is maximized. However, this dimension of study does not consider that not all investors will have all the information available to comprehensively judge the actual level of risk and return before taking decision in RE [7].

To compensate this 'rationale' approach, another dimension of RE study is reviewed looking at the less rational aspects of investors' decision. In a much earlier study conducted by [13], a classification of barriers to the adoption RE technology is developed based on the perception of various stakeholders in India. The authors consider perception on six classification namely awareness and information, financial and economic, market, technical, institutional and regulatory, and behavioral. In a recent study conducted by [4], a set of non-financial determinants are used to determine their effect on investors' choices. Using behavioral finance and institutionalize theory as their basis, the authors conceptualize a model for European investors that consider four non-financial factors i.e. a priori belief, institutional pressure, propensity for radical technological innovations, and the investors knowledge of the RE operational context. As the study concentrate on the non-financial factors, investors direct belief or attitude towards financial aspects of RE investment were excluded.

[4], however, have not explicitly considered the role of psychographic variable particularly on investors' environmental attitude in influencing private individuals' preference for RE investment. This psychographic variables have been tested in several other studies on RE such as [14] and [15]. [14] have found that people with higher environmental attitudes are more likely to invest in RE project and even seem to accept financial disadvantages in return for the environmentally-friendly projects. [15], on the other hand, 
found that while people who perceive that climate change is happening, are more likely to support RE related policy, the belief, however, does not influence how much they are willing to allocate for RE investment.

A review on the investors' behavior literature has also found that Theory of Planned Behavior (TPB) developed by [16] has been widely used in research exploring investors' decision making (see for example [17], [18]). However, this theory has not been explored widely within the context of RE investment. [17], for example, has used a modified TPB to explain Malaysian investors' decision making behavior towards socially responsible investment. TPB, in general encapsulates the role of three determinants i.e. attitudes, subjective norms and perceived behavior in establishing intentions.

Taking into consideration that RE investment is still at infancy stage, it is obvious that understanding drivers of the decision making process of RE investors should be part of the scholarly concern. The above review has shown that few researchers have taken up the challenge and provide a list of potential drivers that can help to explain investors' decision to invest in RE projects. However, to the knowledge of this study, there has been no consideration been made on the role of TPB in explaining investors' intention to invest in RE. It is proposed that several variables being tested in previous RE research can be extended using the TPB.

\section{The INTEGRATEd RE INVESTMENT DECISION MODEL}

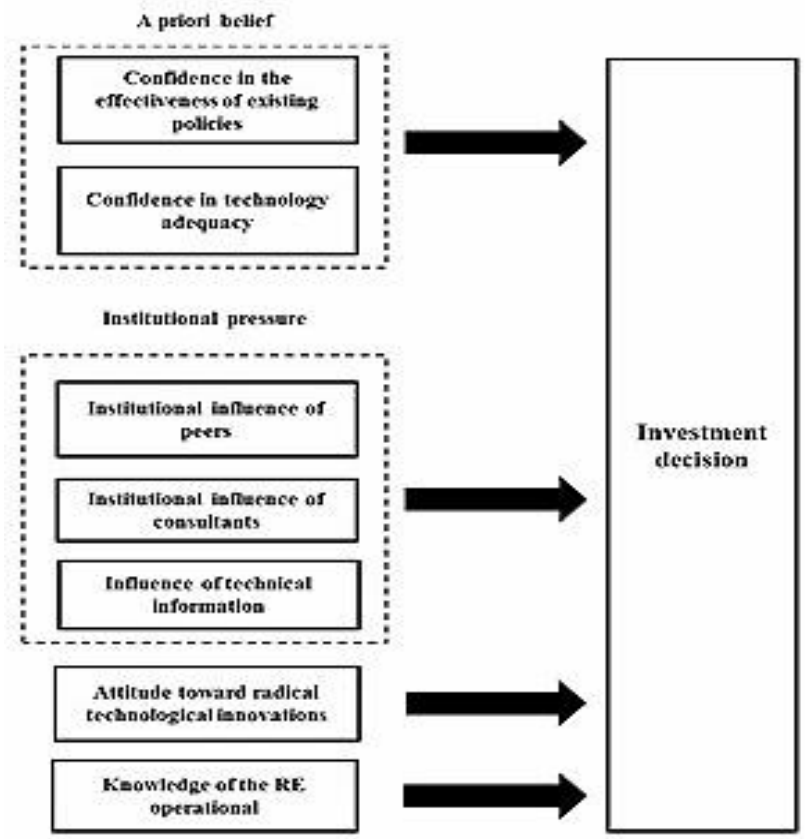

Fig. 1. Investment decision conceptual model proposed by [4].

This study proposes the integration of TPB along with variables identified by previous researchers in RE particularly the model introduced by [4]. As highlighted in previous section, [4] model (as seen in Fig. 1) has been developed largely based on behavioral finance theory as well as institutional theories. It is proposed that the model can also be extended to include determinants from TPB that has been used by previous behavioral studies as major determinants of intention. Previous studies on investment decision of RE (including [4]) have not considered the role of intention as a mediator to behavior of RE investors.

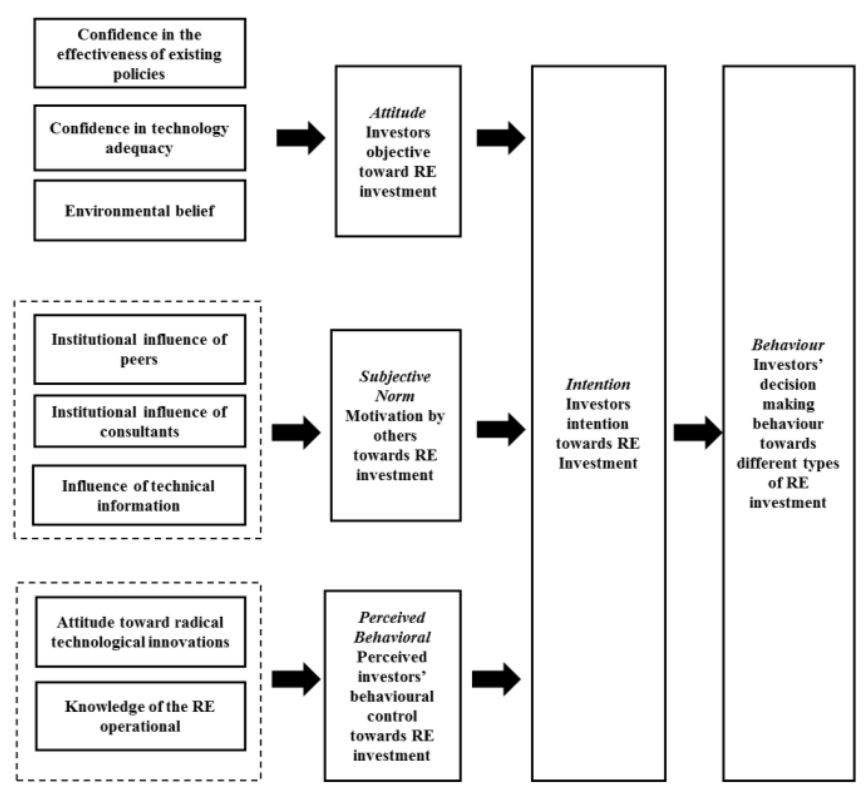

Fig. 2. Integrated RE investment decision model.

Fig. 2 illustrates the new integrated decision making model that has been modified to incorporate the drivers from [4] which is now acting as the explanatory variables to the three attributes under TPB. In TPB model introduced by [16] intention to invest in $\mathrm{RE}$ project is determined by the following three attributes:

\section{A. Attitude}

Within the perspective of this study, attitude is defined as the investors' evaluation of objectives of investing in RE project which in return will stimulate RE decisions. It is proposed that priori belief determinants in [4] can potentially influence investors' attitude. To be more specific, it is expected that prior beliefs about the technical adequacy of the RE technology and the investors' level of confidence in the effectiveness of RE policy measures can potentially influence (or potentially vice versa) investors attitude towards RE investment. In addition to these two determinants, this study also proposes one physiographic determinant i.e. environmental belief as another proxy for attitude. As highlighted before, this determinant has been tested under previous RE study such as [14] and [15].

\section{B. Subjective Norms}

This study defines subjective norms as one's belief about whether significant others think one should invest in RE project. Significant others are individuals or groups whose preferences about a person's behavior in this context are important to him or her [17]. It is proposed that the institutional pressure identified by [4] will emulate investors' perception of whether investing in RE is considered accepted, encouraged, and implemented by their circles of influence. [4] argue that the institutional pressures can be represented by three determinants i.e. institutional influence of peers, institutional influence of external consultants looking for customers in RE fields, and institutional influence from factual information originating either from technical report or from due diligence conducted in house. 


\section{Perceived Behavior Control}

As stipulated by [4] as RE is a new technology, it is expected that it imposes greater uncertainties. In addition, the study also argues that investors' decision to invest is also influenced by the level of knowledge that the investors have on the RE projects that they are going to deployed. This present study proposes that these two determinants will influence investors' perception on the benefits and weaknesses of engaging RE project. Level of knowledge that the investors have on RE (and the technologies that come with it) is expected to play a role in helping investors evaluate the riskiness of the project and eventually influence their perceived behavioral control on the project.

The three TPB attributes is expected to eventually underlie investors' intention to invest in different types of RE technologies and eventually behavior towards RE investment. As illustrated in [17], intention is expected to be motivational factors that can strongly influence how willing people are to perform a behavior - in this case decision making behavior towards RE investment.

\section{CONCLUSION}

The aim of this paper has been to develop a decision making model that integrate drivers identified by previous researchers in RE decision making and the TPB. It is proposed that a comprehensive decision making framework is needed to develop deeper understanding of how individual inform their intention and eventually behavior towards different types of RE investment. While the model is still need to be tested, assessment of this model must not be mistaken for precise representations of individuals' complex behavior and multi-faceted relationship with its surroundings nor does it offers a concrete solution to the regulators. However, the model, once it is supported with empirical evidence, can act as a reference to better understand investors' decision making process that will help the RE industry to attract the badly needed capital for investment in different types of RE technologies. It will also act as a basis for regulators to design a more effective policy instruments and strategies to support the market deployment of RE technologies.

\section{ACKNOWLEDGMENT}

N. Mat Husin and B. Alrazi wish to acknowledge the support given by Universiti Tenaga Nasional (The National Energy University) and its Innovation \& Research Management Center (iRMC) for their continuous support in making sure this research achieves its objective.

\section{REFERENCES}

[1] P. Sadorsky, "Modeling renewable energy company risk," Energy Policy, vol. 40, pp. 39-48, 2012.

[2] Performance Management \& Delivery Unit. Economic transformation programme - Oil, Gas, and Energy. (2013). [Online]. Available: http://etp.pemandu.gov.my/Oil,_Gas_and_Energy-@Oil,_Gas_and_E nergy_-_EPP_10-;_Building_Up_Renewable_Energy_and_Solar_Po wer_Capacity.aspx

[3] F. Muhammad-Sukki et al., "Progress of feed-in-tariff in Malaysia: A year after," Energy Policy, vol. 67, pp. 618-625, 2014.

[4] A. Masini and E. Menichetti, "Investment decisions in the renewable energy sector: An analysis of non-financial drivers," Technological Forecasting \& Social Change, vol. 80, pp. 510-524, 2013.
[5] C. Donovan and L. Nunez, "Figuring what's fair: The cost of equity capital for renewable energy in emerging markets," Energy Policy, vol. 40, pp. 49-58, 2010.

[6] J. I. Munoz, A. A. S. de la Nieta, J. Contreras, and J. L. Bernal-Agustin, "Optimal investment portfolio in renewable energy: The Spanish case," Energy Policy, vol. 37, pp. 5273-5284, 2009.

[7] R. Wustenhagen and E. Menichetti, "Strategic choices for renewable energy investment: Conceptual framework and opportunities for further research," Energy Policy, vol. 40, pp. 1-10, 2012.

[8] Sustainable Energy Development Authority. (2012). Renewable energy status in Malaysia. [Online]. Available: http://www.mida.gov.my/env3/uploads/events/Sabah04122012/SED A.pdf

[9] A. Aqel. Malaysia's renewable energy outlook. [Online]. Available: http://www.greenprospectsasia.com/content/malaysia\%E2\%80\%99s-r enewable-energy-outlook

[10] M. Antonelli et al., "The doping effect of Italian feed-in-tariffs on the PV market," Energy Policy, vol. 67, pp. 583-594, 2014.

[11] S. Jenner, F. Groba, and J. Indvik, "Assessing the strength and effectiveness of renewable electricity feed-intariffs in European Union countries," Energy Policy, vol. 52, pp. 385-401, 2013.

[12] T. K. Boomsma et al., "Renewable energy investments under different support schemes: A real options approach," European Journal of Operational Research, vol. 220, pp. 225-237, 2012.

[13] S. Reddy and J. P. Painuly, "Diffusion of renewable energy technologies - barriers and stakeholders' perspectives," Renewable Energy, vol. 29, pp. 1431-1447, 2004.

[14] J. Gamel, K. Menrad, and T. Decker, "Is it really all about the return on investment? Exploring private wind energy investors' preference," Energy Research \& Social Science, vol. 14, pp. 22-32, 2016.

[15] C. L. Noblet, M. F. Teisl, M. W. Anderson, S. McCoy, and E. Cervone, "Public preferences for investments in renewable energy production and energy efficiency," Energy Policy, vol. 87, pp. 177-186, 2015.

[16] I. Ajzen, "The theory of planned behavior," Organ. Behav. Hum. Decis. Process, vol. 50, no. 2, pp. 179-211, 1991.

[17] A. A. Adam et al., "Socially responsible investment in Malaysia: Behavioral framework in evaluating investors's decision making process," Journal of Cleaner Production, vol. 80, pp. 224-240, 2014.

[18] P. A. Pavlou and M. Fygenson, "Understanding and prediction electronic commerce adoption: An extension of the theory of planned behavior," MIS Q., vol. 30, no. 1, pp. 115-143, 2006.

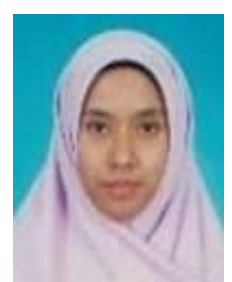

N. Mat Husin obtained her first degree in the area of accounting and finance from Lincoln University, New Zealand in 2000. She then pursued her master's degree in the area of international accounting and consultancy at the University of Reading, United Kingdom in 2003. In 2012, she obtained her PhD degree from Auckland University of Technology (AUT), New Zealand.

She is currently the head of Research Cluster Energy and Social Sustainability. Prior to that, she was the deputy dean of Postgraduate and Research, College of Business Management \& Accounting, National Energy University.

Dr. Mat Husin teaches, researches, and supervises undergraduate and postgraduate students in the area of accounting theory and financial reporting. She has presented and published several papers particularly in the area of sustainability reporting. With her research experience, Dr. Mat Husin has been appointed as a reviewer for conferences such as Asian Forum for Business Communication 2012 Conference and journals such as Asian Academy of Management Journal of Accounting \& Finance.

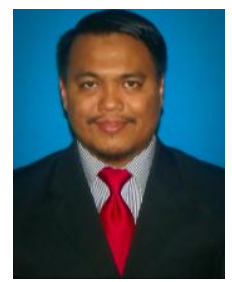

B. Alrazi is a senior lecturer in the Department of Accounting, Universiti Tenaga Nasional. He holds a $\mathrm{PhD}$ (accounting) degree from University of Auckland, New Zealand, an MSc. (accounting) degree from International Islamic University Malaysia; and a bachelor of accounting (Hons.) degree from Universiti Tenaga Nasional, Malaysia. Currently, he is the dean of the College of Business Management and Accounting. He teaches financial accounting, integrated case study, accounting research method, and Islamic accounting courses. He has a deep research interest in the areas of environmental reporting, corporate governance, and accounting from the Islamic perspective. He has published in journals including Accounting and Business Research, Journal of Cleaner Production, and Asian Journal of Business and Accounting. 